УДК 621.391

\title{
МЕТОДИ АНАЛІЗУ СПЕКТРА В КОГНІТИВНИХ РАДІОМЕРЕЖАХ
}

\author{
Канд. техн. наук В.П. Лисечко, О.І. Підченко, О.Л. Анохін, І.І. Сопронюк
}

\section{МЕТОДЫ АНАЛИЗА СПЕКТРА В КОГНИТИВНЫХ РАДИОСЕТЯХ}

\author{
Канд. техн. наук В.П. Лысечко, А.И. Пидченко, О.Л. Анохин, И.И. Сопронюк
}

\section{METHODS OF SPECTRUM SENSING IN COGNITIVE RADIO NETWORKS}

Cand. of techn. sciences V.P. Lysechko, O.I. Pidtchenko, O.L. Anokhin, I.I. Sopronyuk

У статті розглянуто методи загального і локального аналізу спектра для виявлення первинного користувача в когнітивних радіомережах $y$ каналах із завмираннями, затінюваннями та адитивним шумом. Також було побудовано узагальнену модель когнітивної радіомережі і визначено основні поняття когнітивного радіо.

Ключові слова: релеєвські завмирання, когнітивне радіо, затінювання, аналіз спектра, білий шум, функиіональні характеристики приймача.

В статье исследуются методь общего и локального анализа спектра для определения наличия первичного пользователя в когнитивных радиосетях в каналах $c$ релеевскими замираниями, затенениями и аддитивным бельм шумом. Такље была построена обобщенная модель когнитивной радиосети и определень основные понятия когнитивного радио.

Ключевые слова: когнитивное радио, анализ спектра, бельий шум, релеевские замирания, затенения, функциональные характеристики приемника

In the article the methods of global and local analysis of spectrum are investigated for determination of presence of primary (licensed) user in когнитивных radio networks in channels with Rayleigh fading, shadowing and additive white noise. The generalized model of cognitive radio network was also built and the basic concepts of cognitive radio are certain.

Keywords: cognitive radio, the spectrum analysis, white noise, Rayleigh fading, shadowing, receiver operating characteristics

Постановка проблеми. Розвиток безпроводових телекомунікаційних систем, таких як: системи стільникового і супутникового радіозв'язку, локальні безпроводові мережі та Інтернет, став причиною різкого збільшення навантаження на обмежені ресурси радіочастотного спектра. У наш час практично весь частотний діапазон розподілений та ліцензований, що в умовах обмеженості частотного ресурсу призводить до його істотного дефіциту. В результаті впровадження та використання нових видів обслуговування, для роботи яких необхідна наявність вільних частотних діапазонів, стає досить складним, а в деяких випадках зовсім неможливим.

Впровадження технології радіозв'язку 3 використанням механізмів інтелектуального управління (когнітивне радіо) являє собою один із підходів для забезпечення більш ефективного використання радіочастотного спектра за рахунок динамічного та гнучкого управління ним. 
Аналіз літератури. У вітчизняній літературі проблему розгортання когнітивних радіомереж та побудови оптимальних алгоритмів аналізу спектра для точного виявлення первинних (ліцензованих) користувачів недостатньо розглянуто. Тому існує задача дослідження методів та алгоритмів спільного i локального аналізу спектра для виявлення первинного (ліцензованого) користувача в каналах 3 релеєвськими завмираннями, затінюваннями та адитивним білим шумом

Мета статті. Звичайно, у когнітивних терміналах немає жодних або є обмежені дані про первинні сигнали; отже, оптимальна технологія аналізу спектра виявлення енергії [1]. Технологія виявлення енергії для аналізу спектра в окремому когнітивному радіо КР (від англ. - cognitive radio $\mathrm{CR}$ ), що описана у статті, відрізняється простотою, відносною легкістю виконання та низькою обчислювальною складністю [2].

Метою статті $\epsilon$ побудова узагальненої моделі когнітивної радіомережі, а також дослідження оптимальних алгоритмів аналізу спектра для виявлення первинного користувача.

Основний матеріал. 1. Основні визначення. Технічною робочою групою когнітивного радіо було запропоновано визначення когнітивного радіо (КР) [3]: “Когнітивна система радіозв'язку -радіосистема, що використовує технології, які дозволяють ій отримувати знання про своє робоче та географічне середовище, встановлені правила на своєму внутрішньому стані, а також динамічно i автономно коректувати свої робочі параметри i протоколи відповідно до отриманих даних для досягнення встановлених цілей та навчатися за досягнутими результатами".

Когнітивність означає здатність радіосистеми вирішувати такі задачі:

1) оцінка шумової обстановки радіосередовища, виявлення частин спектра, які не використовуються в даний момент часу;
2) аналіз параметрів радіоканалу, оцінка канальної інформації, прогнозування стану радіоканалу;

3) контроль випромінюваної потужності та динамічне управління спектром.

Радіоелектронні засоби когнітивної радіомережі для виконання цих функцій повинні мати у своєму складі елемент, який забезпечує формування/обробку радіосигналів (радіоплатформу); елемент, який здійснює спостереження за радіочастотним спектром (моніторинг спектра); елемент, який здійснює аналіз результатів спостережень i навчання системи (когнітивний або інтелектуальний модуль); елемент, який забезпечує нормативну керованість системи (відповідно до встановлених цілей, правил та методів управління спектром), і елемент, який накопичує знання та отримані дані (база даних). Структурна схема РЕЗ КР, яка виконує дані функції, подана на рис. 1.

За методами аналізу робочого середовища системи КР діляться на дві категорії:

1) системи когнітивного радіо 3 пасивним аналізом експлуатаційного середовища;

2) системи когнітивного радіо $з$ активним аналізом експлуатаційного середовища.

Пасивний аналіз. Перевагою пасивних методів $є$ те, що вони можуть забезпечити зв'язок без завад для первинної системи, оскільки для неї використовуваний спектр визначений апріорі. Вторинна система використовує лише ті частоти, які надані первинною системою або повноважним органом. Проте метод пасивного аналізу збільшує кількість інформації, яка необхідна для управління системою. Значний об'єм інформаційного ресурсу системи, в цьому випадку, може бути відведений для передачі інформації про частоти. Крім того, пасивні підходи не сумісні 3 існуючими системами ліцензування. Вони можуть бути дуже корисні в майбутньому. Відзначимо також, що пасивні методи аналізу можуть бути об'єднані з методами використання спектра по можливості. 


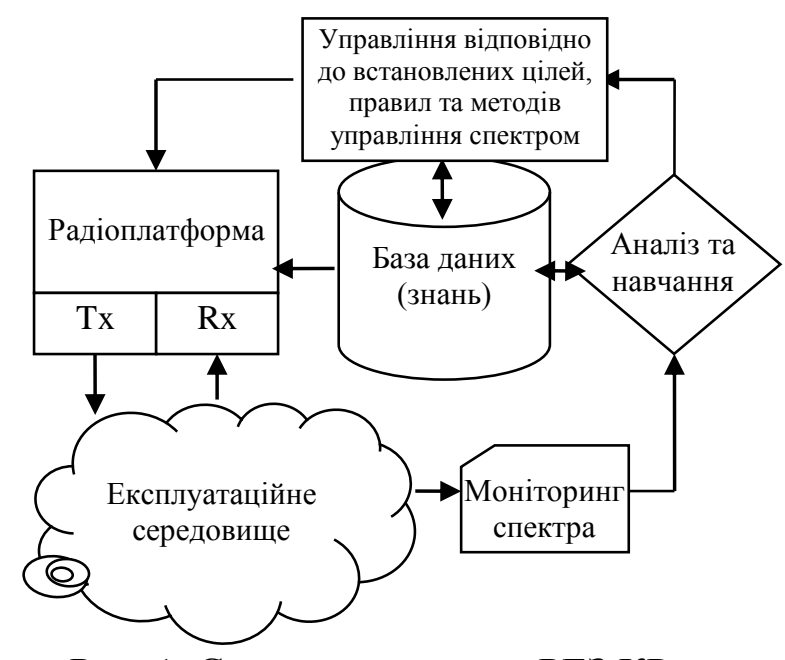

Рис. 1. Структурна схема РЕЗ КР

Активний аналіз. Активний аналіз є способом отримання інформації про поточне використання спектра в експлуатаційному середовищі. В основу метода активного аналізу покладений моніторинг спектра 3 метою виявлення смуг частот, які використовуються іншими системами. Метод вимагає постійного моніторингу експлуатаційного середовища для того, щоб нові первинні користувачі і можливі вакантні канали були своєчасно виявлені.

Залежно від набору функціональних параметрів, які враховуються при прийнятті рішення, можна виділити такі типи когнітивних радіосистем (КРС):

- повне когнітивне радіо ("Mitola radio"): у якому всі можливі для спостереження параметри РЕЗ або безпроводової мережі прийняті до уваги;

- когнітивне радіо на основі аналізу спектра, в якому розглядається лише один параметр - зайнятість радіочастотного спектра.

\section{2. Модель когнітивної радіомережі.} Розглянемо когнітивну радіомережу $3 \mathrm{M}$ користувачами $(i \in\{1,2, \ldots, M\})$ та центром комбінування для аналізу частини спектра діапазону “ $W$ ' з метою виявлення наявності первинного користувача. Кожний когнітивний радіоприймач обладнаний датчиком енергії і незалежно виконує локальний аналіз спектра. Кожен CR здійснює власне спостереження, основуючись на отриманому сигналі: або лише шум, або сигнал 3 шумом. Отже, проблему аналізу спектра можна розглядати як проблему аналізу з двома можливими гіпотезами $H_{0}$ та $H_{1}$, визначену як [4]

$$
x_{i}(t)= \begin{cases}n_{i}(t), & H_{0}, \\ h_{i} S(t)+n_{i}(t), & H_{1},\end{cases}
$$

де $S(t)$ є сигналом первинного користувача 3 рівномірним розподілом і нульовим середнім та дисперсією $\sigma_{S}{ }^{2}$.

Для $i$-го вторинного користувача прийнятий шум змодельований як $n_{i}(t)$, який є випадковим процесом з рівномірним розподілом i нульовим середнім та дисперсією $\sigma_{n}^{2}$, а $h_{i}-$ коефіцієнт підсилення каналу між первинним користувачем та $i-\mu$ вторинним користувачем. $S(t)$ та $n_{i}(t)$ незалежні один від одного. Потужність, передана первинним користувачем, отримується вторинним користувачем, а відношення отриманої потужності до потужності шуму вторинного користувача визначається як значення відношення сигнал/шум (SNR - 
від англ. Signal to Noise Ratio) у датчику енергії. Значення SNR на вході приймача у $i$-го вторинного користувача визначається яК

$$
Y_{i} \cong \frac{E\left[\left|h_{i}\right|^{2}\right] \sigma_{s}^{2}}{\sigma_{n}^{2}} .
$$

Існують два випадки моделі системи. У першому випадку передавач первинного користувача знаходиться далеко від когнітивної радіомережі, i, отже, у всіх вторинних користувачів на входах приймачів можуть бути прийняті приблизно однакові значення SNR. У другому випадку первинний користувач знаходиться недалеко від $M$ вторинних користувачів, і у кожного користувача на вході приймача різне значення SNR, яке залежить від відстані до первинного користувача та умов каналу.

\section{3. Локальний аналіз спектра.} Ефективність даної схеми аналізу спектра істотно обмежена каналом поширення радіохвиль. Як правило, втрати в радіоканалі можуть бути розділені на три групи: втрати на трасі, швидкі завмирання і повільні завмирання [5]. Втрати на трасі враховуються в отриманому значенні SNR в терміналі CR. Швидкі завмирання $€$ випадковою зміною потужності сигналу на вході приймача $\mathrm{CR}$ i характеризуються релеєвським розподілом. Повільні завмирання - повільна зміна потужності прийнятого сигналу. Повільні завмирання часто моделюється як нормальний розподілений випадковий процес із стандартною девіацією, яка залежить від навколишнього середовища [7].

3.1. Аналіз спектра в каналі 3 AWGN. У виявленні енергії, заснованому на аналізі спектра, прийнята радіочастотна енергія в даному каналі або діапазоні частот $W$ вимірюється за часовим інтервалом $T$ для визначення наявності сигналу $S(t)$ первинного користувача.
Добуток ширини смуги на час - ціле число i позначається $N=T W$. Статистична величина $U_{i}$, розрахована для $i$-го користувача,

$$
U_{i}=\sum_{k=1}^{N}\left|x_{i}\left(\frac{k}{W}\right)\right|^{2},
$$

$U_{i}$ порівнюється із зумовленим порогом $\lambda_{i}$ для отримання локального рішення

$$
U_{i} \underset{\substack{<\\ H_{0}}}{\stackrel{H_{1}}{\geq}} \lambda_{i}
$$

Вибір 3 двох альтернативних рішень позначається як $D_{i} ; D_{i}=1$ при $U_{i}>\lambda_{i}$ та $D_{i}=0 \quad$ у інших випадках. $U_{i}-$ сума квадратів $N$ гаусівських випадкових змінних [6]. $U_{i}$ відповідає централізованому хі-квадратному розподілу із ступенем $2 N$, згідно $з$ гіпотезою $H_{0}$, і децентралізованому хі-квадратному розподілу із ступенем $2 N$ та параметру нецентрованості $2 N Y_{i}, \quad$ згідно 3 гіпотезою $H_{1}$. Тому щільність розподілу ймовірності випадкової змінної $U_{i}$, згідно з цими двома гіпотезами, може бути визначена як

$$
f_{U_{i}}(U)=\left\{\begin{array}{lr}
\frac{U^{N-1} e^{-U / 2}}{2^{N} \Gamma(N)}, & H_{0}, \\
\frac{1}{2}\left(\frac{U}{2 N v_{i}}\right)^{(N-1) / 2} e^{-\left(U+2 N v_{i}\right) / 2} I_{N-1}\left(\sqrt{2 N U Y_{i}}\right), H_{1},
\end{array}\right.
$$

де $\Gamma(\cdot)$ - гамма-функція, а $I_{N-1}(\cdot)$ - змінена функція Бесселя першого вигляду.

Для $i$-го користувача ймовірність сигналу помилки $\operatorname{Pr}\left(\mathrm{H}_{1} \mid \mathrm{H}_{0}\right)$ та виявлення $\operatorname{Pr}\left(\mathrm{H}_{1} \mid \mathrm{H}_{1}\right)$ можуть бути отримані 3 (5) та подані як 


$$
\begin{gathered}
P_{f}^{i}=\operatorname{Pr}\left\{U_{i}>\lambda_{i} \mid H_{0}\right\}=\frac{\Gamma\left(N, \lambda_{i} / 2\right)}{\Gamma(N)}, \\
P_{d}^{i}=\operatorname{Pr}\left\{U_{i}>\lambda_{i} \mid H_{1}\right\}=Q_{N}\left(\sqrt{2 N Y_{i}}, \sqrt{\lambda_{i}}\right),
\end{gathered}
$$

де $\Gamma(a, x)$ - неповна гамма-функція;

$$
Q_{N}(a, b) \quad-\quad \text { узагальнена } Q \text {-функція }
$$

Маркума.

Для спрощення (5) може бути побудована апроксимуюча модель для аналізу спектра. При $N$, який прагне до нескінченності (фактично, при $N \geq 10$ [6]), хі-квадратний розподіл, визначений в (5), сходиться до нормального розподілу, тобто

$$
U_{i} \sim\left\{\begin{array}{l}
N\left(N \sigma_{i}^{2}, 2 N \sigma_{i}^{4}\right), \\
N\left(\left(N+Y_{i}\right) \sigma_{i}^{2}, 2\left(N+2 Y_{i}\right) \sigma_{i}^{4}\right), H_{1}
\end{array},\right.
$$

Так само $P_{f}^{i}$ та $P_{d}^{i}$, визначені в (6) і (7), можуть бути апроксимовані як

$$
\begin{aligned}
& P_{f}^{i}=Q\left(\frac{\lambda_{i}-E\left[U_{i} \mid H_{0}\right]}{\sqrt{\operatorname{var}\left[U_{i} \mid H_{0}\right]}}\right)=Q\left(\frac{\lambda_{i}-N \sigma_{i}^{2}}{\sqrt{2 N} \sigma_{i}^{2}}\right), \\
& P_{d}^{i}=Q\left(\frac{\lambda_{i}-E\left[U_{i} \mid H_{0}\right]}{\sqrt{\left.\operatorname{var}\left|U_{i}\right| H_{0}\right]}}\right)=Q\left(\frac{\lambda_{i}-\left(N+v_{i}\right) \sigma_{i}^{2}}{\sqrt{2\left(N+2 v_{i}\right) \sigma_{i}^{2}}}\right),
\end{aligned}
$$

де $E[\cdot]$ та $\operatorname{var}[\cdot]$ позначають очікування i дисперсію відповідно.

\section{2. Аналіз спектра в каналах із завмираннями. Коли вторинний} користувач знаходиться в каналі із завмираннями, коефіцієнт підсилення каналу $h_{i}$ для $i$-го користувача змінюється через завмирання, а $P_{d}^{i}$ стає умовною ймовірністю, що залежить від миттєвого значення відношення сигнал/шум $Y_{i}$. Середня ймовірність виявлення може бути отримана, усереднюючи миттєве значення $P_{f}^{i}$ за статистикою завмирань, де $f_{V}(x)-$ значення SNR на вході приймача.

$$
P_{d, \text { fading }}^{i}=\int_{V} P_{d}^{i}(x) f_{V}(x) d x,
$$

Якщо канал характеризується релеєвськими завмираннями (Rayleigh fading), то $Y_{i}$ розподілено експоненціально, a $\bar{Y}_{i}$ - його середнє значення. Якщо канал характеризується затінюваннями (Shadow fading), то $Y_{i}$ - розподілено логнормально, 3 середнім значенням $\bar{Y}_{i}$, і характеризується дисперсією $\sigma_{d B}$ [4]. Отже,

$f_{V_{i}}(x)=\left\{\begin{array}{lr}\frac{1}{x} \exp \left(-\frac{x}{\bar{V}_{i}}\right) ; & \text { Rayleigh_Fading }, \\ \frac{\xi}{x \sigma_{d B} \sqrt{(2 \pi)}} \exp \left(-\frac{10 \log _{10}(x)-\mu_{x_{d B}}}{2 \sigma_{d B}^{2}}\right) & ; \text { Shadow_Fading, }\end{array}\right.$

де $\xi=10 / \ln (10) ; \quad \mu_{X_{d B}}-$ середнє 3 $x_{d B}=10 \ln (x)$.

Перетворення від лінійного середнього до середнього логарифмічного (в децибелах) може бути отримано як [7]

$$
\mu_{X_{d B}}=10 \log _{10}\left(\bar{Y}_{i}\right)-\frac{\sigma_{d B}^{2}}{2 \xi},
$$

Замінюючи (7) та (11) в (10), для каналу 3 релеєвськими завмираннями середня ймовірність виявлення $i$-го користувача може бути обчислена як [4]

$$
\begin{aligned}
& P_{d, \text { rayl }}^{i}=\int_{V} \frac{1}{x} Q_{N}\left(\sqrt{2 N_{x}}, \sqrt{\lambda_{i}}\right) \exp \left(-\frac{x}{\bar{V}_{i}}\right) d x \\
& =e^{-\lambda_{i} / 2} \sum_{n=0}^{N-2} \frac{1}{n !}\left(\frac{\lambda_{i}}{2}\right)^{N}+\left(\frac{1+\bar{V}_{i}}{\bar{V}_{i}}\right)^{N-1} \\
& \times\left[e^{-\lambda_{i} / 2\left(1+\bar{V}_{i}\right)}-e^{-\lambda_{i} / 2} \sum_{n=0}^{N-2} \frac{1}{n !} \frac{\lambda_{i} \bar{V}_{i}}{2\left(1+\bar{V}_{i}\right)}\right],
\end{aligned}
$$

Для затінювань [7] 


$$
\begin{aligned}
& P_{d, \text { shadow }}^{i}=\int_{V} Q_{N}\left(\sqrt{2 N x}, \sqrt{\lambda_{i}}\right) \frac{1}{x \sigma_{d B} \sqrt{2 \pi}} \\
& \times \exp \left(-\frac{10 \log (x)-\mu_{X_{d B}}}{2 \sigma_{d B}^{2}}\right) d x \\
& =\frac{1}{\sigma_{d B} \sqrt{2 \pi}} \sum_{x=x_{0}}^{x_{f}} Q_{N}\left(\sqrt{2 N x}, \sqrt{\lambda_{i}}\right) \\
& \times \exp \left(-\frac{10 \log (x)-\mu_{X_{d B}}}{2 \sigma_{d B}^{2}}\right) \frac{\Delta x}{x},
\end{aligned}
$$

де $\Delta x$ та $x_{f}$ вибрані для мінімізації числової помилки апроксимації.

3.3. Результати моделювання. Ефективність локального аналізу спектра оцінюється використанням теоретичних результатів і результатів моделювання для побудови графіків функціональних характеристик приймача (графіки ROC від англ. Receiver Operating Characteristic, графік залежності $P_{m}=1-P d$ від $\left.P_{f}\right)$. У моделюванні ймовірність сигналу помилки i помилки виявлення обчислюється порівнянням результатів аналізу спектра із зумовленим порогом. Передбачається, що $N=5$. Рис. 3 ілюструє графіки ROC для локального аналізу спектра в каналі 3 AWGN, релеєвськими завмираннями i затінюваннями при різних значеннях $\sigma_{d B}$. Для порівняння подано результати аналізу спектра в каналі 3 AWGN, результати моделювання перевірені порівнянням 3 аналітичними результатами. 3 рис. 3 видно, що релеєвські завмирання і затінювання погіршують роботу аналізу спектра. Наприклад, у каналі 3 релеєвськими завмираннями для досягнення $P_{m}<10^{-1}$, де $P_{m}=1-P d$, необхідно $P_{f}>0.4$, що призводить до неефективного використання спектра, і навпаки. Так само з рис. 3 видно, що локальний аналіз спектра є важчим при затінюваннях, а із збільшенням завмирань (або $\sigma_{d B}$ ), робота датчика погіршується.

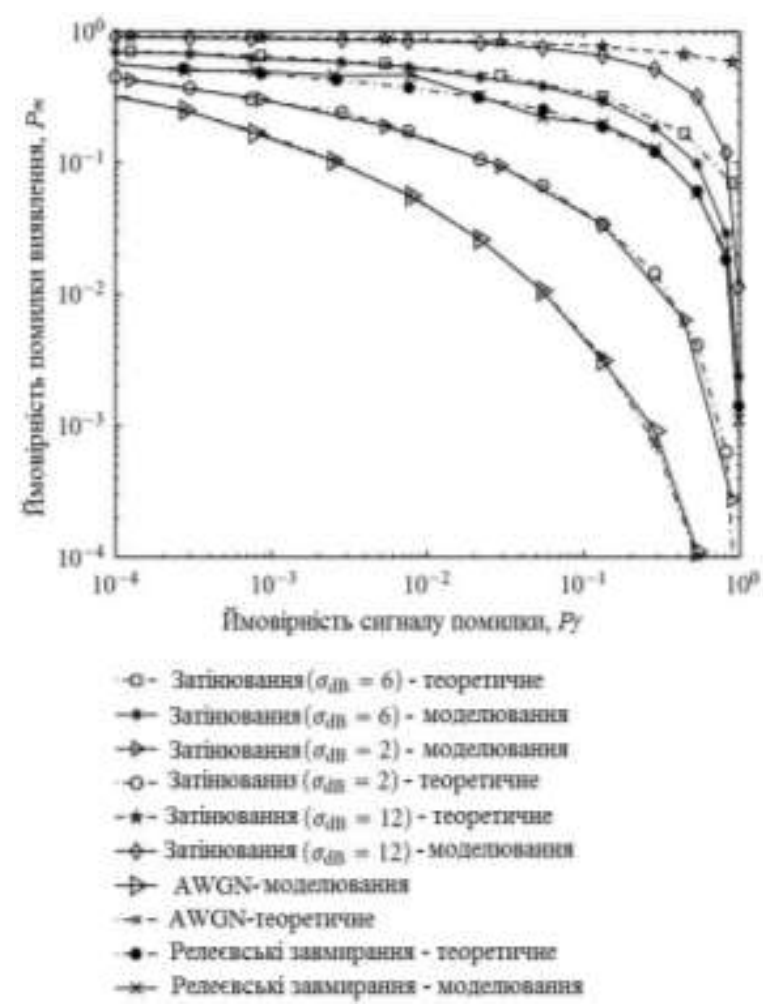

Рис. 2. ROC для локального аналізу спектра в каналах з релеєвськими завмираннями і затінюваннями при $Y=5 \mathrm{~dB}, N=5$ 
Іншим важливим показником, що характеризує ефективність аналізу спектра, $\epsilon$ мінімальне значення SNR, яке можна виявити. Цей показник визначається як найнижче значення SNR, яке алгоритм моніторингу спектра здатний виявити 3 надійністю $P_{f}$ та $P_{d}$ для даного сигналу первинного користувача, умов поширення і часу спостереження. На рис. 3 подано мінімальне значення SNR, що можна виявити, при різних умовах каналу для заданого $P_{f}=10^{-1}$. 3 рис. 3 видно, що затінювання впливає на роботу датчика сильніше, ніж релеєвські завмирання. Як показано на pиc. 3, для досягнення $P_{f}=10^{-1}$ у даному сценарії необхідне значення SNR - приблизно 10 дБ.

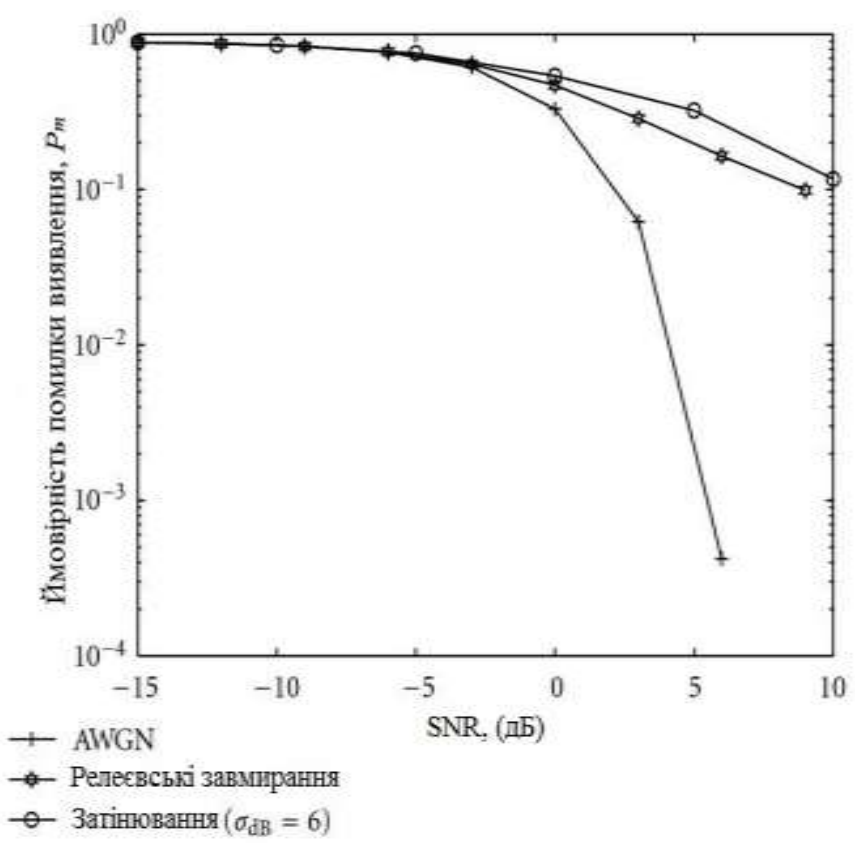

Рис. 3. Залежність ймовірності помилки виявлення від мінімального значення SNR, що можна виявити, в умовах затінювань, при $P_{f}=10^{-1}, Y_{d B}=5, N=5$

Висновки. Розгортання когнітивних радіомереж головним чином залежить від здатності інтелектуальних терміналів точно виявити ліцензованих користувачів, i, отже, мінімізувати внутрішньосистемні завади. Тому моніторинг спектра $\epsilon$ ключовою функціональною можливістю когнітивного радіо. Оскільки результати моніторингу єдиного когнітивного радіотерміналу не завжди достовірні, то взаємодія когнітивних приймачів підвищує рівень виявлення первинних користувачів. В даній статті були проаналізовані алгоритми оптимізації для комбінування жорстких та м'яких рішень при спільному аналізі спектра. Для отримання оптимального правила комбінування центр комбінування повинен точно знати значення SNR y взаємодіючих користувачів, а також умови каналу. Був також проаналізований алгоритм зваженого спільного аналізу спектра, який покращує спільний аналіз 3 точки зору функціональних характеристик приймача. Результати моделювання показують, що проаналізовані алгоритми покращують роботу аналізу спектра $з$ точки зору загальної ймовірності помилки виявлення. 


\section{Список використаних джерел}

1. H. Urkowitz. Energy detection of unknown deterministic signals. - IEEE Proceedings. 1967. - vol. 55. - no. 4. - pp. 523-531.

2. A. Ghasemi and E. S. Sousa. Opportunistic spectrum access in fading channels through collaborative sensing. - IEEE Journal of Communications. - 2007. - vol. 2. - no. 2. - pp. 71-81.

3. Cognitive Radio Definition," Virginia Tech Cognitive Radio Work Group Wiki. Availabile Online: http://support.mprg.org/dokuwiki/doku.php?id=cognitive_radio:definition

4. F.F. Digham, M.S. Alouini, and M. K. Simon. On the energy detection of unknown signals over fading channels. - IEEE Transactions on Communications. - 2007. - vol. 55. - no.1. - pp. 21-24.

5. S. Haykin. Cognitive radio: brain-empowered wireless communications. - IEEE Journal on Selected Areas in Communications. - 2005. - vol. 23. - no. 2. - pp. 201-220. 1996.

6. P.K. Varshney. Distributed Detection and Data Fusion, Springer, Secaucus, NJ, USA,

7. A. Goldsmith, Wireless Communications, Cambridge University Press, New York, NY, USA, 2005.

8. I. Akyildiz, W.-Y. Lee, M. C. Vuran, and S. Mohanty. A survey on spectrum management in cognitive radio networks. - IEEE Communications Magazine. - 2008. - vol. 46. - no.4. - pp. 40-48.

9. F.E. Visser, G.J. M. Janssen, and P. Pawełczak. Multinode spectrum sensing based on energy detection for dynamic spectrum access in Proceedings of the 67th IEEE Vehicular Technology Conference (VTC '08), pp. 1394-1398, June 2008.

10. E. Visotsky, S. Kuffher, and R. Peterson. On collaborative detection of TV transmissions in support of dynamic spectrum sharing, in Proceedings of the 1st IEEE International Symposium on New Frontiers in Dynamic Spectrum Access Networks (DySPAN '05), pp. 338-345, December 2005.

11. T. Weiss, J. Hillenbrand, and F. Jondral. A diversity approach for the detection of idle resources in spectrum pooling systems, in Proceedings of the 48th International Scientific Colloquium, pp. 37-38, September 2003.

Рецензент д-р техн. наук, професор С.І. Приходько

\footnotetext{
Лисечко Володимир Петрович, кандидат технічних наук, доцент кафедри транспортного зв’язку

Анохін Олег Леонідович, студент

Сопронюк Іван Іванович, аспірант

Підченко Олександр Іванович, студент.

Lysechko V.P., cand. of techn. sciences, Pidtchenko O.I., Anokhin O.L., Sopronyuk I.I.
} 